\title{
Experience with the Use of Global Reference Fields for Compilation of Aeromagnetic Data for Europe
}

\author{
Thomas WoNIK \\ Niedersächsisches Landesamt für Bodenforschung, Stilleweg 2, D-3000 Hannover 5I, \\ Federal Republic of Germany
}

(Received September 11, 1989; Revised April 27, 1990)

\begin{abstract}
A compilation of aeromagnetic data for Europe is in progress to produce a map showing crustal anomalies of total intensity for the epoch 1980.0 and the altitude $3000 \mathrm{~m}$ above m.s.l. and to interpret it in terms of large-scale features in the crust. A report is given of our experience with secular variation and with the reference field which has to be subtracted from the total intensity values to obtain crustal anomalies.

When aeromagnetic surveys are compiled, data from observatories and repeat stations are necessary in order to estimate secular variation with sufficient precision. Data from repeat stations are more detailed and realistic than computed values from global reference field models. The secular variations computed from three different reference field models differ considerably.

The influence of the reference field and its truncation level on the shape of anomalies is examined by calculating differences between the reference fields. The decision to use the DGRF 1980 model for publishing a map showing European crustal anomalies for 1980.0 is based on the fact that this model gives a better approximation of observed values at observatories and repeat stations in Central Europe than two other models. These differences between observed and computed values are partly caused by inhomogeneous input data used for the calculation of reference fields. The input data is inhomogeneous because each observatory publishes their annual mean values based on its own observatory standard and not on the International Magnetic Standard.
\end{abstract}

\section{Introduction}

One of the aims of the research project titled "Collection and Representation of the Magnetic Crustal Anomalies in Western Europe and their Interpretation" is to compile total intensity values of the geomagnetic field for as large an area of Europe as possible. These values are referred to the same epoch (1980.0) and the same altitude (3000 $\mathrm{m}$ above m.s.l.). After subtraction of a suitable reference field, the remaining anomalies will be interpreted in terms of large-scale features of the Earth's crust. Therefore the degree of misfit at the boundaries of adjacent surveys should be less than $10 \mathrm{nT}$. To obtain a uniform map showing crustal anomalies of the total intensity, two parameters are of decisive importance:

1) secular variation (SV), because each survey was referred to a different epoch and

2) the reference field, describing the core's contribution to the Earth's magnetic field.

In this context the following questions arise, to which answers are given below:

- How can the SV for Europe be calculated? 
- What global reference field is best for the purpose of compiling aeromagnetic data for Europe?

\section{Secular Variation}

To estimate SV with sufficient precision for compiling aeromagnetic surveys, it is necessary to make repeat measurements at geomagnetic stations.

The field differences (total intensity) between 1965.0 and 1982.5 obtained by repeat measurements at geomagnetic stations in the Federal Republic of Germany (VOPPEL and WIENERT, 1974; Schulz, personal communication) and France (GILBERT and LE MOUËL, 1984) can be seen in Fig. 1. Field differences for this period at some nearby observatories taken from GoLOVKOV et al. (1983) are also shown in this figure. In Fig. 2 these results are compared with those obtained by calculating the field difference (1982.5 to 1965.0) at the same stations using Definitive Geomagnetic Reference Field (DGRF) 1980 and DGRF 1965 (IAGA DIVISION I WORKING GROUP 1, 1986). It can be seen that the range of values differs considerably in these two figures: The data from the geomagnetic stations in the Federal Republic of Germany (Fig. 1) show increases from 470 to $540 \mathrm{nT}$. The field difference between 1965.0 and 1980.0 computed from the difference between the DGRF 1980 and DGRF 1965 (Fig. 2) varies from 500 to $525 \mathrm{nT}$. The difference between them is plotted in Fig. 3 to emphasize the distinction between the two data sets. The contours run E-W and vary from $25 \mathrm{nT}$ in southern Germany to $-5 \mathrm{nT}$ in northern Germany. A difference of about $30 \mathrm{nT}$ over a period of 17.5 years is observed between the results of the two methods of calculating field differences between 1965.0 and 1982.5 ! This figure clearly shows that the repeat measurements should not be replaced by computed values from DGRF.

Results of such ground measurements together with the observatories' mean values were used to estimate SV for each period between 1980.0 and the respective epoch of survey using a quadratic polynomial for the whole of Europe. This procedure works since it successfully obtains differences in total intensity between adjacent surveys of less than $10 \mathrm{nT}$.

\section{A Suitable Reference Field}

The determination of a reference core field is of necessity somewhat arbitrary because its spectrum partially overlaps the spectrum of the crustal field. Since sources in both the crust and core are unknown, the two components are impossible to separate. An approximation can be reached based on the fact that the spectrum of the whole internal field has two different slopes above and below degree 13. The low-degree part of the spectrum is assigned to the core and the remainder to the crust. However, minor contributions from the crust are concealed in the low-degree part of the spectrum and vice versa (MEYER et al., 1983). These hidden contributions cannot be isolated. Thus, if a reference field truncated at degree 13 is subtracted from the total field intensity, one is eliminating not only the core field but also a field caused by unknown parts of the crust.

Three reference field models were tested: DGRF 1980, CAIN M051782 (CAIN et al., 1984) and GSFC (12/83) (LANGEL and ESTES, 1985); these will be referred to as DGRF, CAIN, and GSFC, respectively. A figure after the model name indicates the truncation level of the main-field terms, e.g. "CAIN 13" means the CAIN M051782 model truncated 


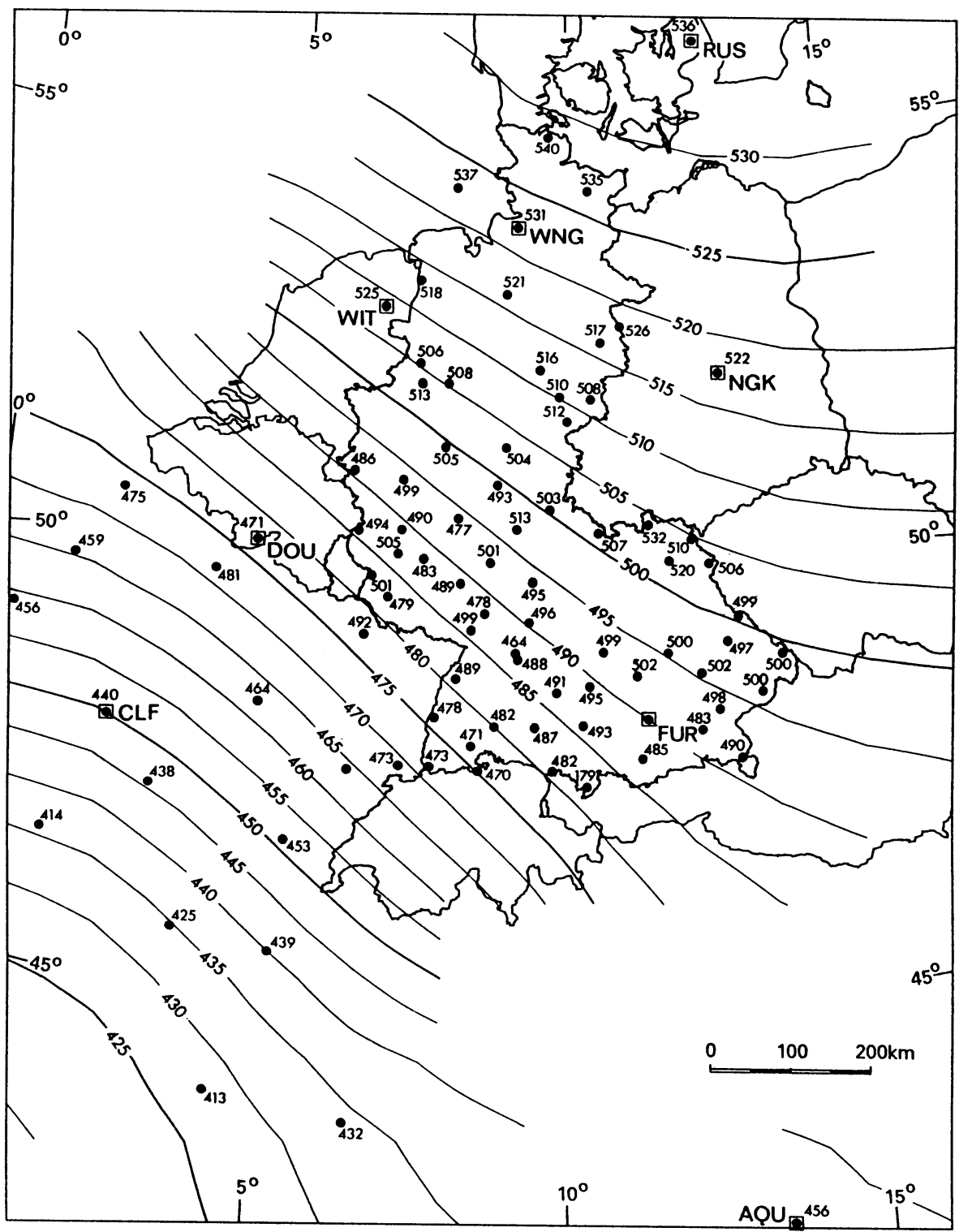

Fig. 1. Field differences (total intensity) for the Federal Republic of Germany and France for the period 1965.0 to 1982.5 (in nT) calculated from repeat station data and observatories. Names of observatories are abbreviated by three letters: RUS: Rude Skov; NGK: Niemegk; AQU: L'Aquila; CLF: Chambon-la-Forêt; DOU: Dourbes; WIT: Witteveen; WNG: Wingst; FUR: Fürstenfeldbruck.

at degree and order 13.

\subsection{Differences in secular variation computed by reference fields}

The different results of calculating field differences of the total intensity between 1982.5 and 1980.0 for an altitude of $3000 \mathrm{~m}$ using these three reference fields are shown in 


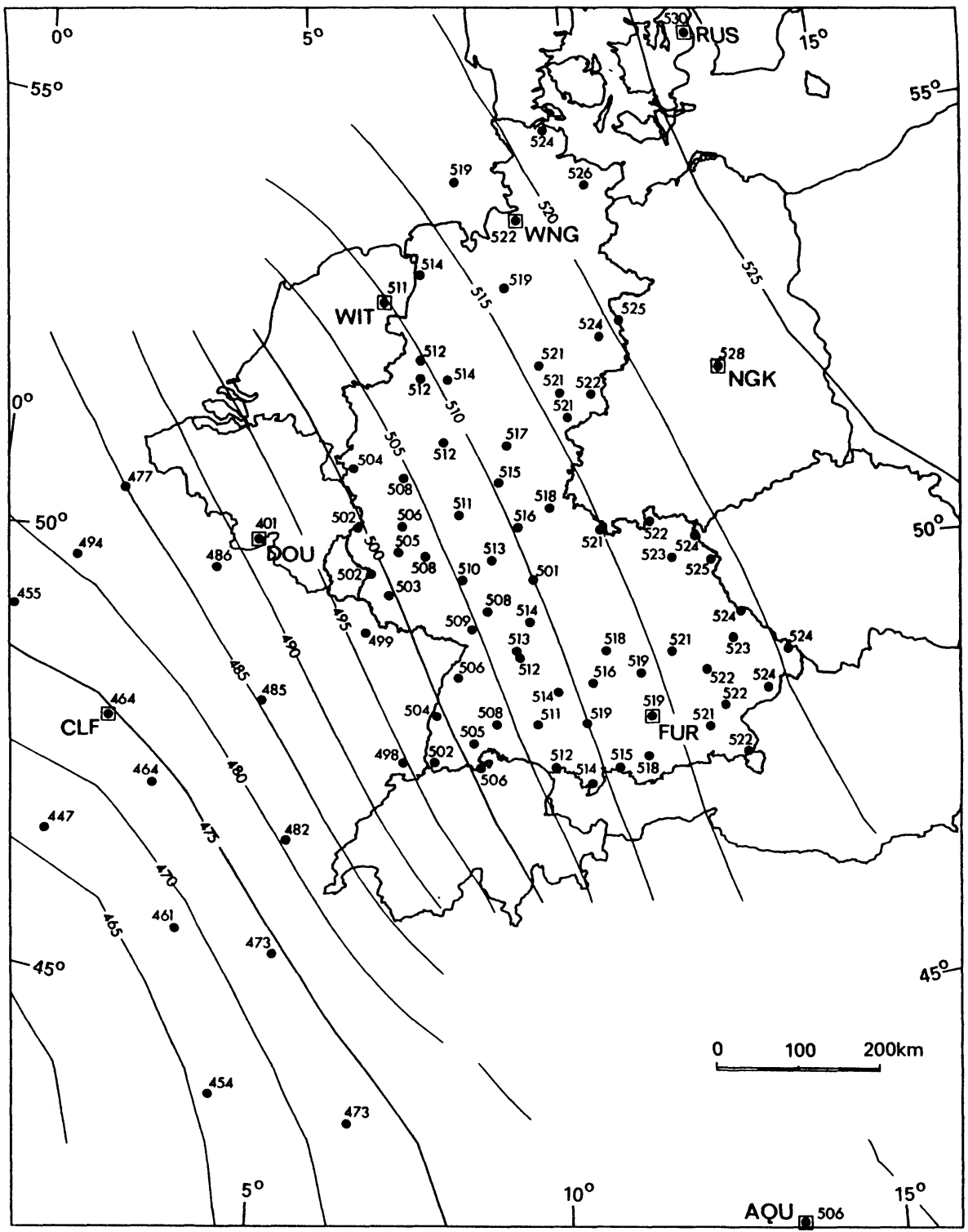

Fig. 2. Field differences (total intensity) for the Federal Republic of Germany and France for the period 1965.0 to 1982.5 (in nT) calculated from the difference DGRF 1980 (epoch 1982.5) minus DGRF 1965 (epoch 1965.0) for the geomagnetic stations and observatories. For abbreviations of observatories see Fig. 1.

Figs. 4-6. One fact common to all examined reference fields is remarkable: In Europe only small gradients of SV occur in this period, especially if compared with southern Africa or northern America.

Field differences of total intensity for the time interval 1982.5 and 1980.0 computed 


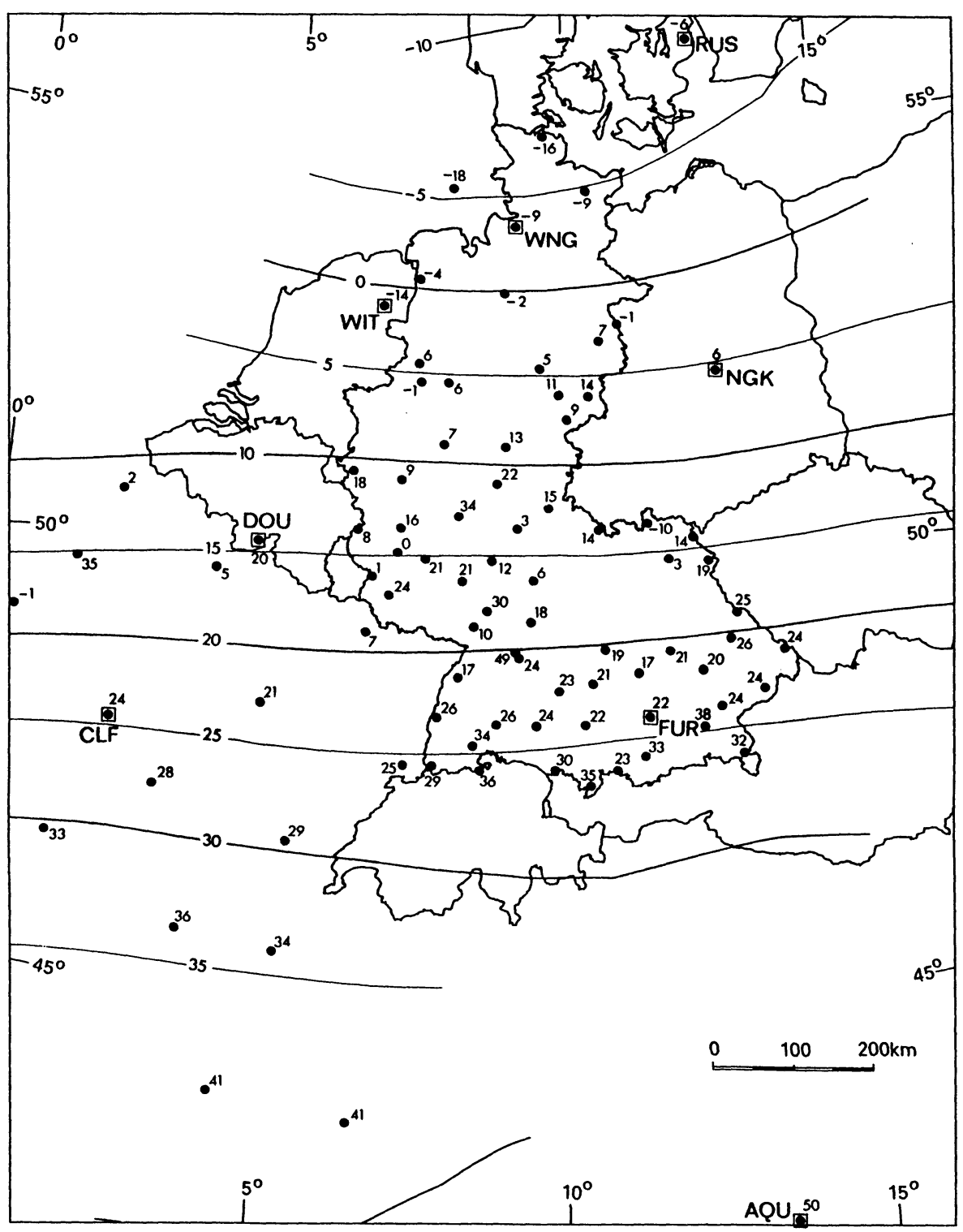

Fig. 3. Difference between the results of two methods of calculating field differences (total intensity) for the geomagnetic stations of the Federal Republic of Germany and France and some nearby observatories for the period 1965.0 to 1982.5 (in nT): field difference calculated from the DGRF models (Fig. 2) minus field difference calculated from repeat station data and observatories (Fig. 1). For abbreviations of observatories see Fig. 1.

by DGRF (Fig. 4) and GSFC (Fig. 5) show quite a similar pattern. The field difference calculated with the CAIN model (Fig. 6) is obviously different, especially for Europe. The field difference in Europe is much smaller in the CAIN model and shows a strong gradient for Scandinavia. 


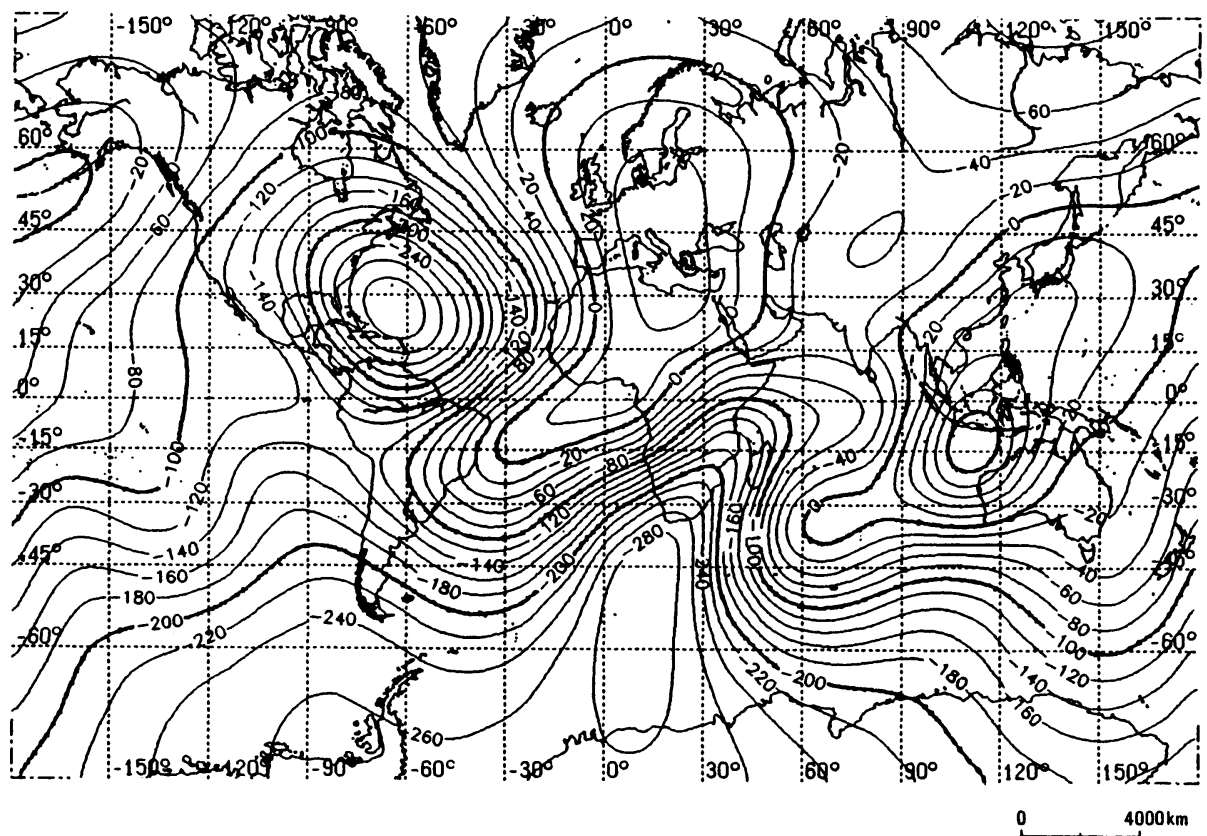

Fig. 4. Field differences (total intensity) for the period 1980.0 to 1982.5 (in nT) calculated for the altitude $3000 \mathrm{~m}$ above m.s.l. with the DGRF 1980 model. A truncation level of degree and order 8 was used for the secular variation coefficients. Contour interval is $20 \mathrm{nT}$. Mercator projection.

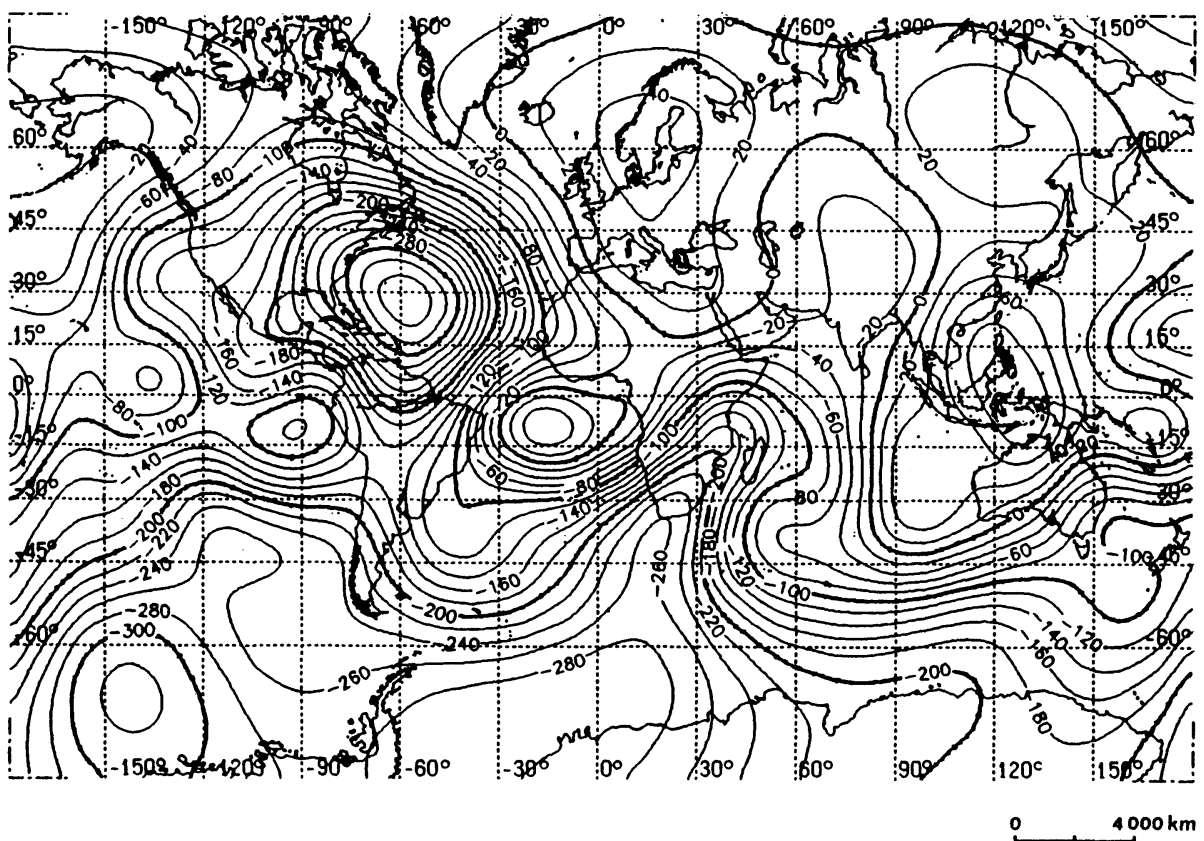

Fig. 5. Field differences (total intensity) for the period 1980.0 to 1982.5 (in nT) calculated for the altitude $3000 \mathrm{~m}$ above m.s.l. with the GSFC model. A truncation level of degree and order 10 was used for the secular variation coefficients. Contour interval is $20 \mathrm{nT}$. Mercator projection. 


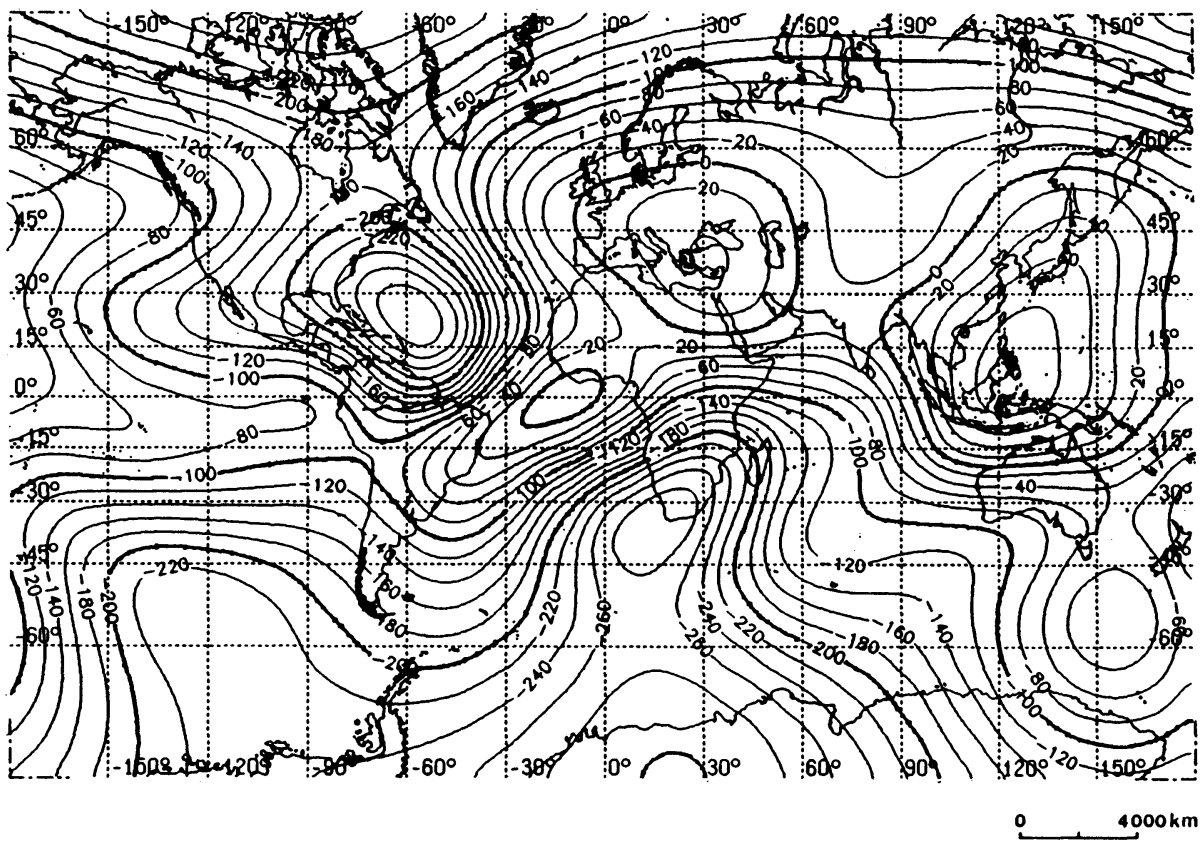

Fig. 6. Field differences (total intensity) for the period 1980.0 to 1982.5 (in $\mathrm{nT}$ ) calculated for the altitude $3000 \mathrm{~m}$ above m.s.l. with the CAIN model. A truncation level of degree and order 7 was used for the secular variation coefficients. Contour interval is $20 \mathrm{nT}$. Mercator Projection.

\subsection{Influence of the reference fields and their truncation level on the shape of magnetic anomalies}

Crustal magnetic anomalies are obtained by subtracting a reference field approximating the magnetic field of the core from total intensity values. The shape of the anomalies is influenced by the choice of reference field. This influence can be seen most clearly, if the differences between these reference fields are examined, e.g. CAIN 13 minus GSFC 13 (Fig. 7). In both cases the total intensity field was calculated for 1980.0 and $3000 \mathrm{~m}$ above m.s.l. The differences between these reference fields determined from Magsat data are quite small: nowhere more than $\pm 25 \mathrm{nT}$. Figure 7 shows that, especially in the case of Europe, the same anomaly pattern is obtained when either CAIN 13 or GSFC 13 is used as a reference field. A constant anomaly level difference of only about $3 \mathrm{nT}$ would be observed in Europe. Differences in other parts of the Earth are not discussed in this paper.

Figure 8 shows CAIN 10 minus DGRF 10, again computed for the epoch 1980.0 and altitude $3000 \mathrm{~m}$. For Europe the differences vary from $-5 \mathrm{nT}$ in Spain to $18 \mathrm{nT}$ in Sweden - this is too much if our aim is to interpret long wavelength anomalies.

The decision about the largest degree and order that should be used to eliminate the core field in reference field models in order to obtain crustal anomalies presents a further difficulty already been mentioned in Section 3. A plot (Fig. 9) of the differences between CAIN 13 and CAIN 10 (i.e. the field contributions of degree and order 11 through 13) shows the influence of using CAIN 13 instead of CAIN 10 as reference field. Note that in this figure the contour spacing is twice as large as in Figs. 7 and 8 and that four very large 


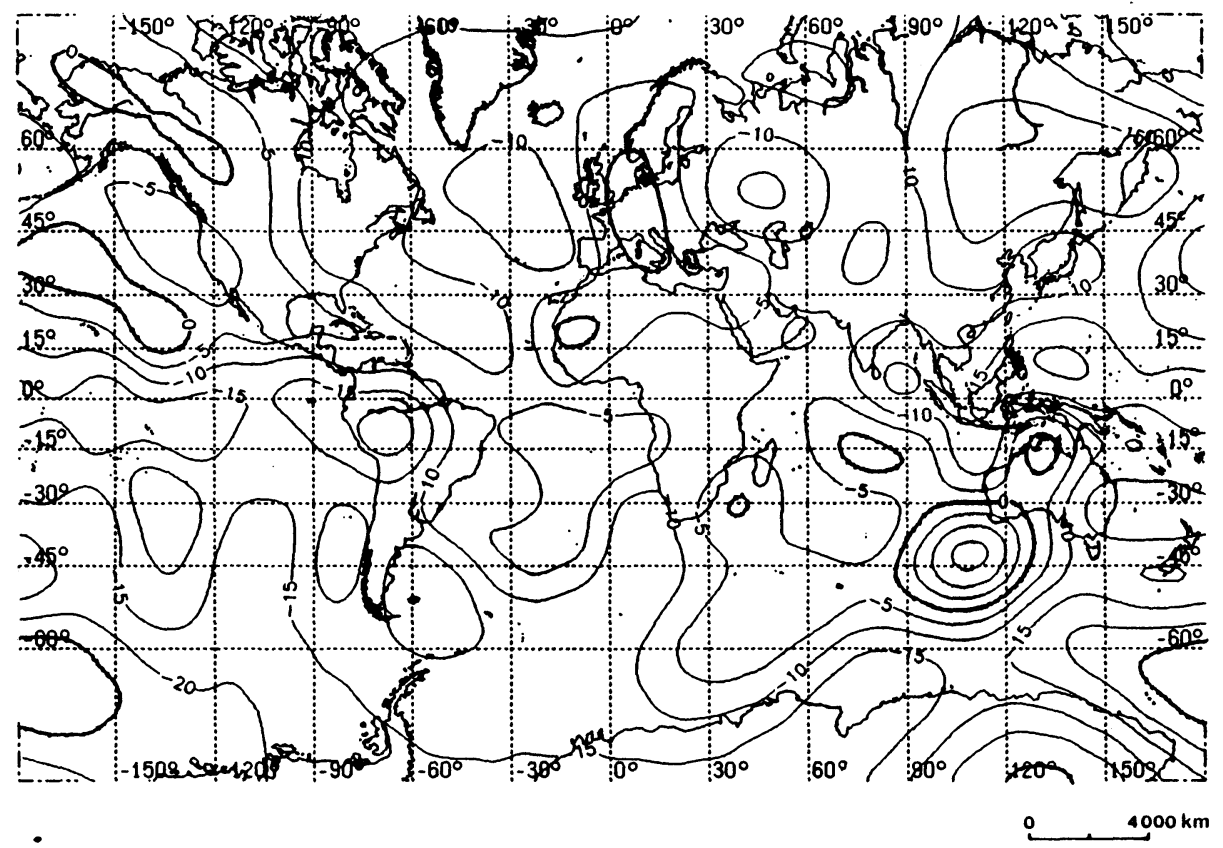

Fig. 7. Difference between the results of two models for calculating total intensity values for the altitude $3000 \mathrm{~m}$ above m.s.l. and for the epoch 1980.0 (in nT): CAIN 13 minus GSFC 13. Contour interval is $5 \mathrm{nT}$. Mercator projection.

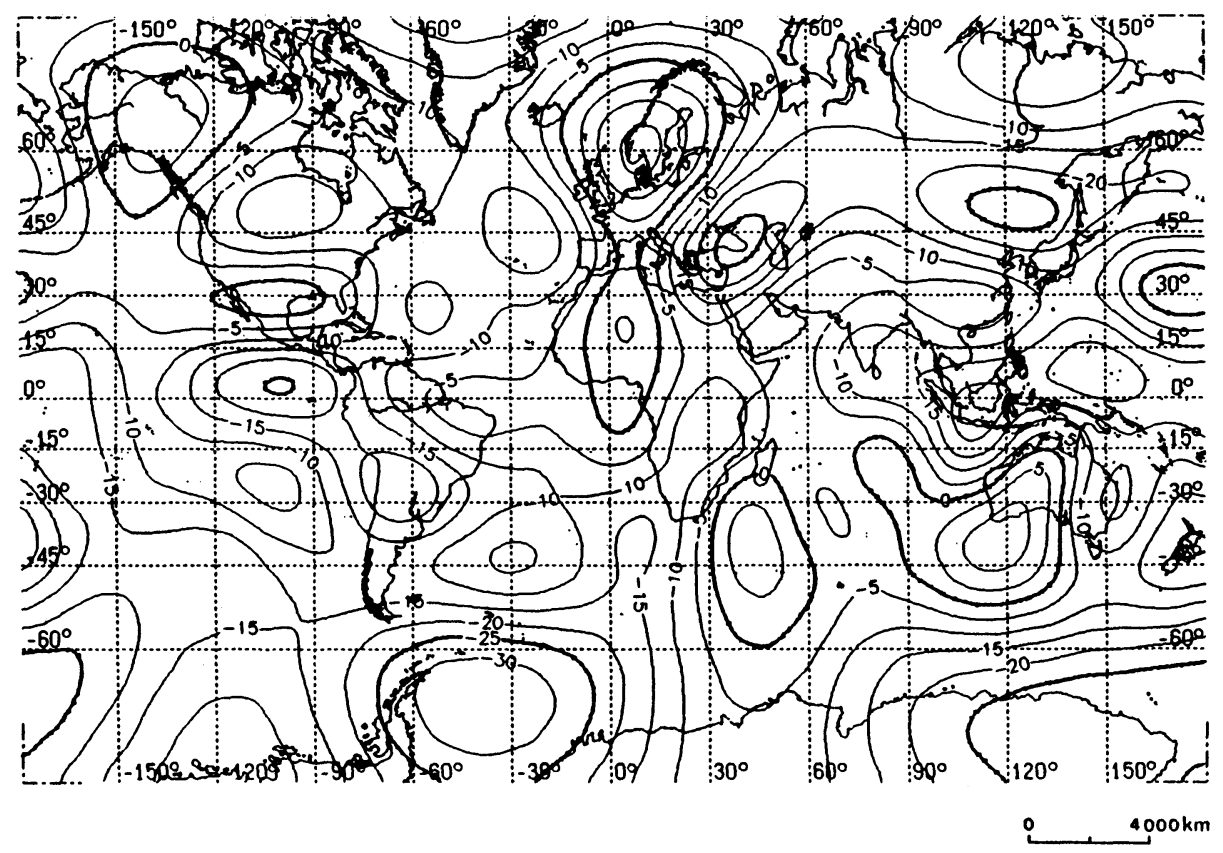

Fig. 8. Difference between the results of two models for calculating total intensity values for the altitude $3000 \mathrm{~m}$ above m.s.l. and for the epoch 1980.0 (in $\mathrm{nT}$ ): CAIN 10 minus DGRF 10. Contour interval is $5 \mathrm{nT}$. Mercator projection. 


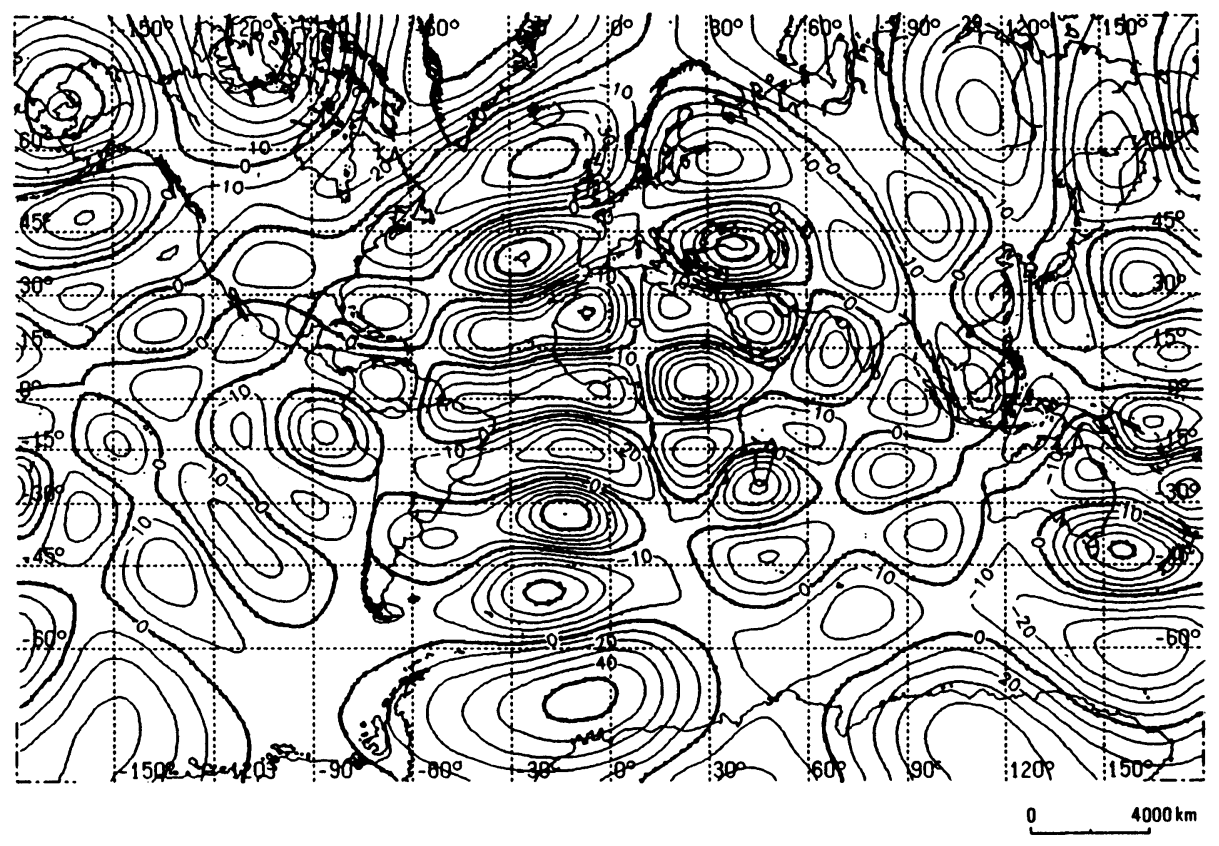

Fig. 9. Influence of truncation level on anomaly pattern: The difference between the results of CAIN 13 minus CAIN 10 for calculating total intensity values for the altitude $3000 \mathrm{~m}$ above m.s.l. and for the epoch 1980.0 (in nT). Contour interval is $10 \mathrm{nT}$. Mercator projection.

extrema appear at the "corners" of Europe:

- south of Iceland $\left(59^{\circ} \mathrm{N}, 20^{\circ} \mathrm{W}\right)$ a minimum of $-57 \mathrm{nT}$,

- near Leningrad (USSR) $\left(59^{\circ} \mathrm{N}, 32^{\circ} \mathrm{E}\right)$ a maximum of $45 \mathrm{nT}$,

- Black Sea $\left(41^{\circ} \mathrm{N}, 38^{\circ} \mathrm{E}\right)$ a minimum of $-58 \mathrm{nT}$,

- Azores $\left(39^{\circ} \mathrm{N}, 27^{\circ} \mathrm{W}\right)$ a maximum of $62 \mathrm{nT}$.

It is conceivable that the anomaly pattern itself is influenced strongly by the reference field and truncation level used.

\subsection{Comparison of observed and calculated total intensity values for Central Europe}

The mean values of ten Central European observatories and 78 repeat stations in France and the Federal Republic of Germany are compared in Fig. 10 with the mean values calculated using reference field models for the same locations taking their elevations into consideration. This was done to obtain further criteria for choosing the most suitable reference field model for Europe. The values listed in the table on the right are plotted on the left side. For the sake of simplicity the values for the two epochs are connected by a straight line. The nearest mean value to the observed values, for both 1982.5 and 1980.0, are those computed from DGRF. The difference amounts to $6 \mathrm{nT}$ for both epochs. Thus, the SV predicted by the DGRF for this period is realistic, as can be seen from the slopes of the two lines. The SV of CAIN is too small. It is only $18 \mathrm{nT} / 2.5 \mathrm{a}$ compared with $47 \mathrm{nT} / 2.5$ a obtained from observations and DGRF. The values obtained from GSFC 10 and GSFC 13 differ from the observed mean values by 7 to $20 \mathrm{nT}$ (Fig. $10)$. 


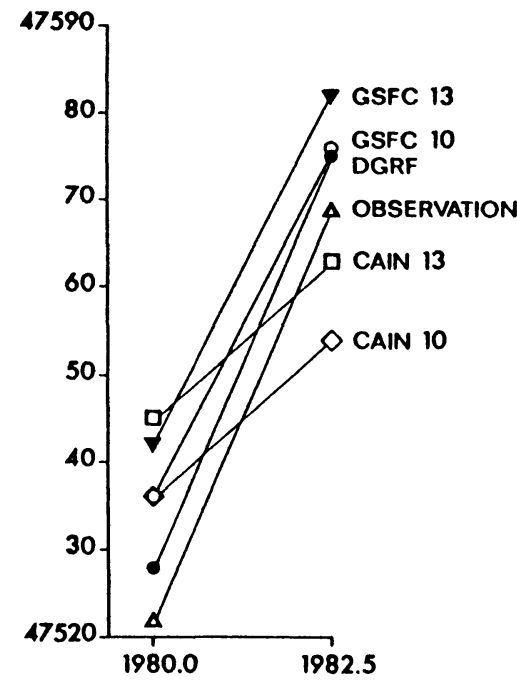

\begin{tabular}{|c|c|c|c|c|c|c|}
\hline $\begin{array}{c}\text { Epoch } \\
\text { observed } \\
\text { value }\end{array}$ & $\begin{array}{c}\text { DGRF } \\
\text { N } 10\end{array}$ & $\begin{array}{c}\text { CAIN } \\
\text { C 10 }\end{array}$ & $\mathbf{N}-13$ & $\mathbf{N}-10$ & $\mathbf{N}-13$ \\
\hline 1982.5 & 47569 & 47575 & 47554 & 47563 & 47576 & 47582 \\
1980.0 & 47522 & 47528 & 47536 & 47545 & 47536 & 47542 \\
\hline
\end{tabular}

Fig. 10. Comparison of observed total intensity values and those computed from global field models (in nT). The "observed values" are the means of data from ten Central European observatories and 78 secular stations in the Federal Republic of Germany and France.

It was decided to use the DGRF 1980 model as the reference field for the compilation of aeromagnetic data for Europe.

\section{Observatory Standard versus International Magnetic Standard}

Figure 10 shows greater or lesser differences between the observed total intensity values and those calculated from global field models in Central Europe. Most of the values measured at repeat stations and observatories show only small local (crustal) anomalies - the anomalous field in Central Europe is very smooth compared with the field that can be observed elsewhere, e.g, in Scandinavia. So, a better correspondence between observed and computed values could be expected.

An avoidable source of error in calculation of global reference field models is the fact that published input data are incorrect or inhomogeneous. Most observatories publish annual mean values using their own observatory standard (OBS). Each OBS is based on measurements with a magnetic theodolite at the respective observatory over a long period of time, e.g. a SCHULZE 75 magnetic theodolite on Pier NE for the Wingst observatory (DEUTSCHES HYDROGRAPHISCHES INSTITUT, 1986). Since each observatory has its own instrument and, therefore, its own standard, the difference between OBS and the International Magnetic Standard (IMS) varies from one observatory to the other. The IMS is defined by the gyromagnetic ratio of the proton, for which IAGA has adopted the value $26751.3 * 10^{4} \mathrm{~T} / \mathrm{s}$. Measurements done with a proton magnetometer normally fulfill this requirement. The differences between OBS and IMS are mentioned in some publications such as the yearbooks from the Fürstenfeldbruck, Wingst, WienKobenzl and L'Aquila observatories. The differences in total intensity (OBS minus IMS) are $28 \mathrm{nT}, 12 \mathrm{nT}, 12 \mathrm{nT}$, and $21 \mathrm{nT}$, respectively. The annual mean values for all the 
geomagnetic observatories in the world given by GoLOVKov et al. (1983) can be used only to calculate relative values for one observatory at a time. It is misleading that these annual mean values are given as absolute values. They are referred to the respective OBS and not to the IMS.

Repeat station data or survey data, which are also used to compute reference field models, may be subject to the same source of error. Time reduction of the data from the geomagnetic survey of Switzerland in 1978.0 was done using the observatory recordings from Fürstenfeldbruck. The annual mean value referred to the OBS was used when the survey data for the 1978.0 epoch were reduced. Consequently, all the published total intensity values (FISCHER et al., 1979) are too high by $28 \mathrm{nT}$; this is the difference (OBS to IMS) at Fürstenfeldbruck.

The influence of this practice of publication of annual mean values on the field models and on magnetic anomalies cannot be estimated by the author. The inhomogeneity of the input data could be avoided by referring all magnetic field values to IMS.

The author is grateful to Prof. A. Hahn for helpful discussions. This project is supported by the Deutsche Forschungsgemeinschaft.

\section{REFERENCES}

Cain, J. C., D. R. Schmitz, and L. Muth, Small-scale features in the earth's magnetic field observed by Magsat, J. Geophys. Res., 89, 1070-1076, 1984.

Deutsches Hydrographisches InStitut, Erdmagnetisches Jahrbuch Nr. 27, Numerische Ergebnisse und Magnetogramme Wingst, Hamburg, 1986.

Fischer, G., P.-A. Schnegg, and J. Sesiano, A new geomagnetic survey of Switzerland, Géol. Suisse-Série Géophysique, 19, 1979.

GiLbert, D. and J. L. Le MouëL, Reseau magnétique de répétition de la France Campagne 1982, Institut de Physique du Globe Observations magnétiques, 50, Paris, 1984.

Golovkov, V. P., G. I. Kolomijtzeva, L. P. Konyaschenko, and G. M. Semyonova, The summary of the annual mean values of magnetic elements at the world magnetic observatories (issue XVI), Academy of Sciences of the USSR, Moscow, 1983.

IAGA Division I Working Group I, International Geomagnetic Reference Field revision 1985, Geophys. J. R. astr. Soc., 85, 1986.

LANGel, R. A. and R. H. Estes, The near-earth magnetic field at 1980 determined from Magsat data, $J$. Geophys. Res., 90, 2495-2509, 1985.

Meyer, J., J.-H. Hufen, M. Siebert, and A. Hahn, Investigations of the internal geomagnetic field by means of a global model of the earth's crust, J. Geophys., 52, 71-84, 1983.

VopPel, D. and K. WiEnerT, Die geomagnetische Vermessung der Bundesrepublik Deutschland, Epoche 1965.0, Dt. hydrogr. Z., 27, 49-56, 1974. 